\title{
Cell-laden alginate dialdehyde-gelatin hydrogels formed in 3D printed sacrificial gel
}

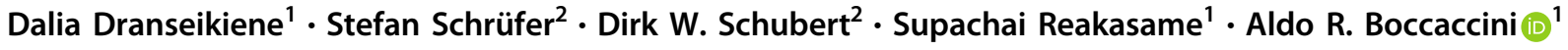

Received: 13 October 2019 / Accepted: 20 February 2020 / Published online: 9 March 2020

(c) The Author(s) 2020

\begin{abstract}
Alginate dialdehyde-gelatin (ADA-GEL) hydrogels have been reported to be suitable matrices for cell encapsulation. In general, application of ADA-GEL as bioink has been limited to planar structures due to its low viscosity. In this work, ring shaped constructs of ADA-GEL hydrogel were fabricated by casting the hydrogel into sacrificial molds which were 3D printed from 9\% methylcellulose and 5\% gelatin. Dissolution of the supporting structure was observed during the $1^{\text {st }}$ week of sample incubation. In addition, the effect of different crosslinkers $\left(\mathrm{Ba}^{2+}\right.$ and $\left.\mathrm{Ca}^{2+}\right)$ on the physicochemical properties of ADA-GEL and on the behavior of encapsulated MG-63 cells was investigated. It was found that $\mathrm{Ba}^{2+}$ crosslinked network had more than twice higher storage modulus, and mass decrease to $70 \%$ during incubation compared to $42 \%$ in case of hydrogels crosslinked with $\mathrm{Ca}^{2+}$. In addition, faster increase in cell viability during incubation and earlier cell network formation were observed after $\mathrm{Ba}^{2+}$ crosslinking. No negative effects on cell activity due to the use of sacrificial materials were observed. The approach presented here could be further developed for cell-laden ADA-GEL bioink printing into complex 3D structures.
\end{abstract}

\section{Graphical Abstract}
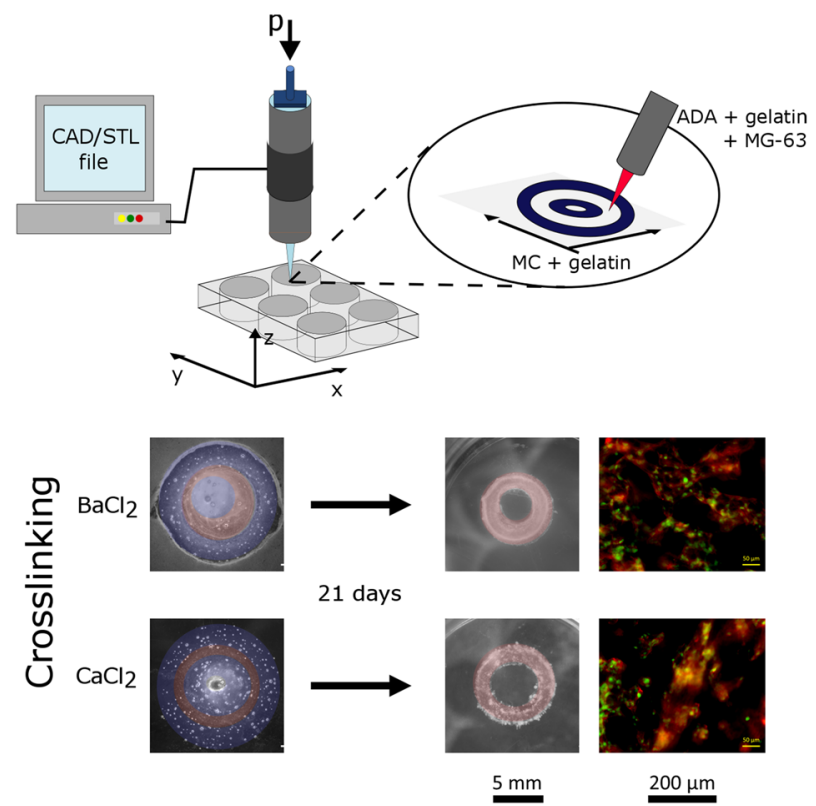

Supplementary information The online version of this article (https:// doi.org/10.1007/s10856-020-06369-7) contains supplementary material, which is available to authorized users.

Aldo R. Boccaccini

aldo.boccaccini@ww.uni-erlangen.de

1 Institute of Biomaterials, University of Erlangen-Nuremberg, 91058 Erlangen, Germany
2 Institute for Polymer Materials, University of ErlangenNuremberg, 91058 Erlangen, Germany 


\section{Introduction}

Biofabrication encompasses processing techniques that allow to create 3D structures of cell-laden hydrogels for tissue engineering applications [1]. Different strategies have been used in order to provide mechanical support to $3 \mathrm{D}$ printed constructs like depositing bioinks into a liquid bath $[2,3]$ or the co-printing of hard [4] and soft [5] supporting materials. Methylcellulose (MC) hydrogels have also been tested as a sacrificial material for 3D printing [6].

Alginate dialdehyde-gelatin (ADA-GEL) hydrogel has been used for cell encapsulation and it has been shown to exhibit good cell adhesion, proliferation and migration properties [7-9]. The benefit of using such hydrogel is that two advantages-mild ADA crosslinking with divalent ions and cell adhesion to GEL-can be combined as the two components (ADA and GEL) form a covalent bond via Schiff's base reaction $[9,10]$. In this work, $3 \mathrm{D}$ printed sacrificial MC based structures were used for casting cell-laden ADA-GEL hydrogel matrices. The possibility to use $\mathrm{Ba}^{2+}$ ions for ADA crosslinking instead of $\mathrm{Ca}^{2+}$ in order to improve the mechanical stability of the constructs was proposed, following recent previous results on similar alginate based hydrogels [5]. In vitro cell studies were performed in order to preliminary assess the potential of the presented biofabrication approach for tissue engineering applications.

\section{Materials and methods}

\subsection{ADA-GEL hydrogel}

\subsubsection{Hydrogel preparation}

ADA was synthesized from sodium alginate (MW 100,000-200,000 $\mathrm{g} / \mathrm{mol}$, Sigma-Aldrich, USA) following the process reported by Zehnder et al. [8]. According to previous work of our group, this process results in a degree of oxidation of ADA of approx. 30\% [10]. To prepare ADA-GEL, equal volumes of filtered 5\% (w/v) ADA and 5\% (w/v) GEL Type A (300 Bloom, Sigma, USA) solutions were stirred together for $10 \mathrm{~min}$. The mixture was then casted, crosslinked by covering with $0.1 \mathrm{M} \mathrm{CaCl}_{2}$ (VWR, Belgium) or $0.1 \mathrm{M} \mathrm{BaCl}_{2}$ (Merck $\mathrm{KGaA}$, Germany) for $15 \mathrm{~min}$, and washed three times with Hank's balanced salt solution (HBSS, Sigma-Aldrich, USA).

\subsubsection{Physicochemical properties}

Mechanical properties of ADA-GEL were determined by using disc-shaped samples $(n=3,16 \mathrm{~mm}$ of diameter and thickness of approximately $1 \mathrm{~mm}$ ) subjected to a frequency sweep in compressive deformation mode to determine storage $\left(\mathrm{E}^{\prime}\right)$ and loss $\left(\mathrm{E}^{\prime \prime}\right)$ moduli at room temperature by
DMTA. A suitable pre-load $(40 \mathrm{~g})$ and strain amplitude $(0.1 \%)$ were determined by previous amplitude sweeps.

Degradation of ADA-GEL was evaluated by incubating ADA-GEL disks in Dulbecco's modified Eagle's medium (DMEM, Gibco, Germany) supplemented with $10 \%$ (v/v) fetal bovine serum and $1 \%(\mathrm{v} / \mathrm{v})$ penicillin-streptomycin (both Sigma-Aldrich, Germany) (the same DMEM was used for cell growth) under cell culture conditions $\left(37^{\circ} \mathrm{C}\right.$, $95 \%$ relative humidity, $5 \% \mathrm{CO}_{2}$ ). Mass change was calculated at defined time points. In parallel, the chemical composition of samples which were incubated for 7, 14, 21, 28 days was investigated by using attenuated total reflection Fourier-transform infrared spectroscopy (ATR FTIR) (IRAffinity-1S, Shimadzu, Japan). The medium was changed three times a week following the same procedure used for cell culture studies.

\subsection{Cell encapsulation in ADA-GEL ring structures}

\subsubsection{Sample preparation}

Sacrificial gel containing 9\% (w/v) MC (Sigma, USA) and 5\% (w/v) GEL was used. This particular composition of the sacrificial gel was obtained from the printing tests of different gel formulations consisting of various concentrations of MC and GEL (data not shown here). Sacrificial gel was transferred into an autoclaved cartridge with a conical nozzle (G22, Nordson EFD, Germany). The cartridge was then placed in a 3D printer (BioScaffolder GeSiM 2.1, GeSiM, Germany). The sacrificial gel was printed as two concentric rings with diameters of 4.4 and $10 \mathrm{~mm}$. The formed well between them was then filled with $70 \mu \mathrm{l}$ ADA-GEL containing osteosarcoma cells MG-63 (Sigma-Aldrich, Germany) at the concentration of $1 \times 10^{6}$ cells $/ \mathrm{ml}$. The samples were crosslinked by covering with $\mathrm{CaCl}_{2}$ or $\mathrm{BaCl}_{2}$ and washed three times with HBSS. The ring-shaped constructs were afterwards incubated in DMEM for 21 days under cell culture conditions.

\subsubsection{Cell activity monitoring}

Cell viability was monitored by using the WST-8 assay kit (Sigma-Aldrich, Germany) which was applied according to the manufacturer's protocol. SYTOX ${ }^{\mathrm{TM}}$ green nucleic acid stain and rhodamine phalloidin (both Invitrogen ${ }^{\mathrm{TM}}$, Molecular Probes $^{\circledast}$ by Life Technologies ${ }^{\mathrm{TM}}$, USA) were used for staining cell nuclei and actin filaments, respectively, for fluorescence microscopy (Axio Observer Scope D1, Carl Zeiss AG, Germany).

\subsection{Statistical analysis}

Statistical analyses were performed by one-way analysis of variance (ANOVA) with Bonferroni means comparison. 


\section{Results and discussion}

\subsection{ADA-GEL hydrogel properties}

DMTA measurements showed higher mechanical properties of $\mathrm{BaCl}_{2}$ crosslinked samples in comparison to $\mathrm{CaCl}_{2}$ crosslinked samples (Fig. 1a). Moreover, storage modulus $\left(\mathrm{E}^{\prime}\right)$ was found to be greater than the loss modulus $\left(\mathrm{E}^{\prime \prime}\right)$ for both sample groups showing dominating elastic behavior. The $\mathrm{E}^{\prime}$ increased with frequency indicating the viscoelastic behavior of the materials [9]. Small standard deviation between the measurements (5-6\%) suggests that the sample crosslinking reached saturation and was reproducible.

Sample degradation (mass loss) is shown in Fig. 1b. In the case of $\mathrm{BaCl}_{2}$ crosslinking, the sample mass rapidly decreased to $85 \pm 1 \%$ during the first 3 days and then decreased further until a final value of $69 \pm 4 \%$ at 28 days of incubation. In case of $\mathrm{CaCl}_{2}$ crosslinking, a higher weight loss was detected. In the first 3 days the sample mass already decreased to $74 \pm 9 \%$ and was further reduced to a final value of $42 \pm 3 \%$ at day 28 . The main difference between the two samples is given by the contribution of ADA dissolution to the overall degradation. $\mathrm{CaCl}_{2}$ crosslinked samples tend to loosen due to weaker bonds and higher exchange of ions with $\mathrm{Na}^{+}$from the medium [11]

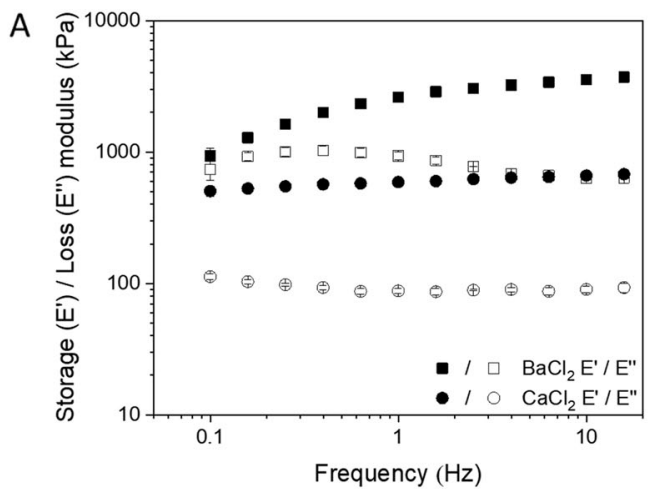

C

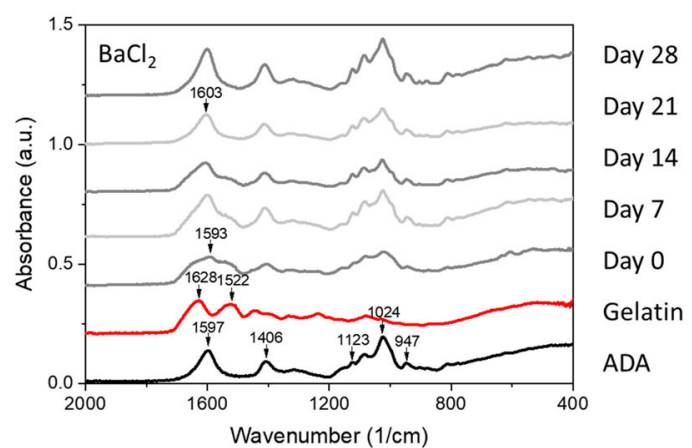

Fig. 1 Properties of 2.5\% ADA + 2.5\% GEL samples crosslinked with $\mathrm{BaCl}_{2}$ and $\mathrm{CaCl}_{2}$ : a DMTA measurements showing storage and loss moduli; b Degradation in DMEM over a time period of 28 days; that can result in the loss of the crosslinks that form the ADA network. Therefore, ADA molecules may be released together with GEL. The degradation of $\mathrm{BaCl}_{2}$ crosslinked samples is then mainly related to the release of uncrosslinked GEL.

FTIR spectra of each gel component were examined (Fig. 1c). Two peaks at 1628 and $1522 \mathrm{~cm}^{-1}$ of the GEL spectrum indicate amide I and amide II peaks [10]. For ADA, typical peaks of asymmetric (at $1597 \mathrm{~cm}^{-1}$ ) and symmetric (at $1406 \mathrm{~cm}^{-1}$ ) $\mathrm{COO}^{-}$vibration, $\mathrm{C}-\mathrm{O}$ stretching at $947 \mathrm{~cm}^{-1}, \mathrm{C}-\mathrm{C}$ stretching at $1123 \mathrm{~cm}^{-1}$ and $\mathrm{C}-\mathrm{O}-\mathrm{C}$ stretching at $1024 \mathrm{~cm}^{-1}$ were found [12,13]. Samples after mixing and crosslinking exhibited specific peaks. In case of $\mathrm{BaCl}_{2}$ crosslinking, a broad peak in the range $1630-1530 \mathrm{~cm}^{-1}$ was formed with distinguishable high peak at $1593 \mathrm{~cm}^{-1}$ and shoulder on the right side (1560-1543 $\mathrm{cm}^{-1}$ ). In case of $\mathrm{CaCl}_{2}$ crosslinking, a broad double peak at 1618 and $1558 \mathrm{~cm}^{-1}$ was found for the sample before incubation. With both crosslinkers, this peak was the result of overlapping peaks of amide I and the ones that correspond to the formation of Schiff's base bond due to crosslinking between ADA and GEL [9]. The peak remained for the first 14 days of incubation and became narrower on day 21 and shifted to $1603 \mathrm{~cm}^{-1}$ for $\mathrm{BaCl}_{2}$ and to $1609 \mathrm{~cm}^{-1}$ for $\mathrm{CaCl}_{2}$. This indicates that gelatin was being released during the incubation.
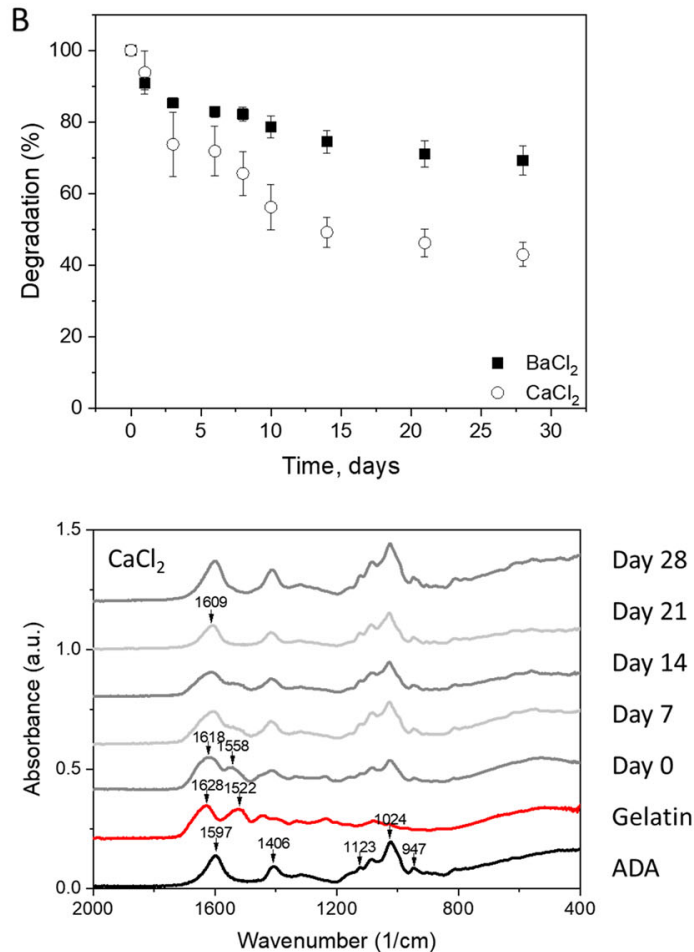

c FTIR spectra obtained at different time points of incubation in DMEM (the relevant peaks are discussed in the text) 


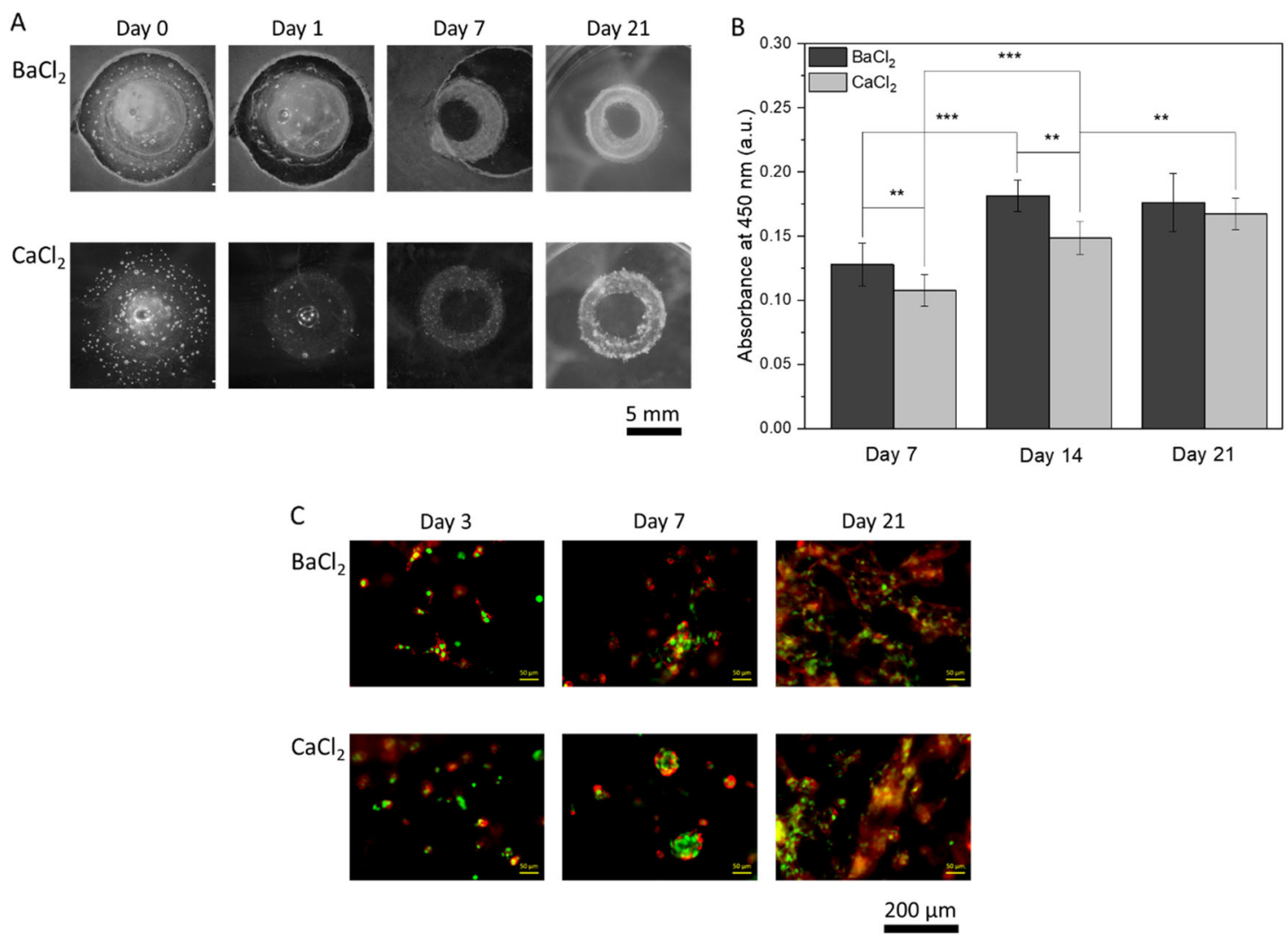

Fig. 2 ADA-GEL ring samples formed with sacrificial hydrogel: a Light microscopy images; b Change in cell viability during the incubation period; c Fluorescence microscopy images

\subsection{Hydrogel casting with sacrificial structure}

Samples containing two sacrificial rings and cell-laden hydrogel were successfully prepared (Fig. 2a). Full dissolution of the sacrificial gel was observed upon 7 days without additional swelling or disruption of the ADA-GEL ring structure. After measuring the development of cell viability (Fig. 2b), it was noticed that during the first 2 weeks of incubation the values significantly increased for both types of samples. In addition, samples crosslinked with $\mathrm{BaCl}_{2}$ had significantly higher values of cell viability than the samples crosslinked with $\mathrm{CaCl}_{2}$. After the 3 rd week only in the case of $\mathrm{CaCl}_{2}$ crosslinked sample cell viability significantly increased further and reached a comparable value to the one of $\mathrm{BaCl}_{2}$ crosslinked samples. This result was also noticed when analyzing fluorescence images (Fig. 2c). Cells in $\mathrm{BaCl}_{2}$ crosslinked samples started to spread and formed an extended network already after 2 weeks, while cells in $\mathrm{CaCl}_{2}$ crosslinked samples grew in more globular structures which connected with each other during the second half of the incubation period. Such growth pattern in case of $\mathrm{CaCl}_{2}$ crosslinking has been previously reported by Zehnder et al. [8]. It has been shown in literature that alginate scaffolds crosslinked with sufficient amount of $\mathrm{BaCl}_{2}$ for $2 \mathrm{~min}$, in addition to $\mathrm{CaCl}_{2}$ crosslinking, exhibited cell viability of over $88 \% 11$ days post-printing [2]. The authors attributed such result to the possibility of maintaining the mechanical properties of the gel rather than to the type of ions used. The anchoring density that may be higher in $\mathrm{BaCl}_{2}$ crosslinked samples might also influence cell attachment [14]. The increase of cell viability with time in case of $\mathrm{CaCl}_{2}$ crosslinking could be due to the ECM forming molecules secreted in the gel by the cells themselves [15]. The present results thus show that the combination of sacrificial structures and a suitable crosslinking process of the ADA-GEL bioink represents a suitable approach for the biofabrication of 3D structures, namely ring forms (Fig. 2a) as well as grid structures depicted in Fig. S1 (Supplementary information).

\section{Conclusions}

The formation of alginate dialdehyde-gelatin cell-laden hydrogels into ring-shaped structures by using $3 \mathrm{D}$ printed methylcellulose based sacrificial materials was successfully achieved in this work. Slower increase in cell viability was identified in samples crosslinked with $\mathrm{CaCl}_{2}$ in comparison to those crosslinked with $\mathrm{BaCl}_{2}$. This result could be attributed to differences in gel stiffness as samples crosslinked with 
$\mathrm{BaCl}_{2}$ exhibited higher elastic moduli and lower weight loss during the incubation period. Further studies considering different alginate dialdehyde-gelatin crosslinking methods could help to understand the factors defining the different cell growth patterns observed in this study. Moreover, the use of a $3 \mathrm{D}$ printed sacrificial gel as introduced in this work could be transferred to other materials like collagen that gels at $37^{\circ} \mathrm{C}$ in longer periods of time.

Acknowledgements DD and SR would like to thank the German Academic Exchange Service (DAAD) for financial support. Support from Collaborative Research Centre TRR 225 "From the fundamentals of biofabrication towards functional tissue models," funded from German Research Foundation (DFG) (Projects A01 and A07), is acknowledged. Open Access funding provided by Projekt DEAL.

\section{Compliance with ethical standards}

Conflict of interest The authors declare that they have no conflict of interest.

Publisher's note Springer Nature remains neutral with regard to jurisdictional claims in published maps and institutional affiliations.

Open Access This article is licensed under a Creative Commons Attribution 4.0 International License, which permits use, sharing, adaptation, distribution and reproduction in any medium or format, as long as you give appropriate credit to the original author(s) and the source, provide a link to the Creative Commons license, and indicate if changes were made. The images or other third party material in this article are included in the article's Creative Commons license, unless indicated otherwise in a credit line to the material. If material is not included in the article's Creative Commons license and your intended use is not permitted by statutory regulation or exceeds the permitted use, you will need to obtain permission directly from the copyright holder. To view a copy of this license, visit http://creativecommons. org/licenses/by/4.0/.

\section{References}

1. Malda J, Visser J, Melchels FP, Jüngst T, Hennink WE, Dhert WJA, et al. 25th anniversary article: engineering hydrogels for biofabrication. Adv Mater. 2013;25:5011-28.
2. Tabriz AG, Hermida MA, Leslie NR, Shu W. Three-dimensional bioprinting of complex cell laden alginate hydrogel structures. Biofabrication. 2015;7:45012.

3. Soltan N, Ning L, Mohabatpour F, Papagerakis P, Chen X. Printability and cell viability in bioprinting alginate dialdehydegelatin scaffolds. ACS Biomater Sci Eng. 2019;5:2976-87.

4. Zehnder T, Freund T, Demir M, Detsch R, Boccaccini AR. Fabrication of cell-loaded two-phase 3D constructs for tissue engineering. Materials. 2016;9:887.

5. Distler T, Ruther F, Boccaccini AR, Detsch R. Development of 3D biofabricated cell laden hydrogel vessels and a low-cost desktop printed perfusion chamber for in vitro vessel maturation. Macromol Biosci. 2019;19:1900245.

6. Ahlfeld T, Köhler T, Czichy C, Lode A, Gelinsky M. A methylcellulose hydrogel as support for 3D plotting of complex shaped calcium phosphate scaffolds. Gels. 2018;4:E68.

7. Leite ÁJ, Sarker B, Zehnder T, Silva R, Mano JF, Boccaccini AR. Bioplotting of a bioactive alginate dialdehyde-gelatin composite hydrogel containing bioactive glass nanoparticles. Biofabrication. 2016;8:35005.

8. Zehnder T, Boccaccini AR, Detsch R. Biofabrication of a coculture system in an osteoid-like hydrogel matrix. Biofabrication. 2017;9:25016.

9. Grigore A, Sarker B, Fabry B, Boccaccini AR, Detsch R. Behavior of encapsulated MG-63 cells in RGD and gelatine-modified alginate hydrogels. Tissue Eng Part A. 2014;20:2140-50.

10. Sarker B, Papageorgiou DG, Silva R, Zehnder T, Gul-E-Noor F, Bertmer M, et al. Fabrication of alginate-gelatin crosslinked hydrogel microcapsules and evaluation of the microstructure and physico-chemical properties. J Mater Chem B. 2014;2: 1470.

11. Mørch YA, Qi M, Gundersen POM, Formo K, Lacik I, SkjåkBraek G, et al. Binding and leakage of barium in alginate microbeads. J Biomed Mater Res A. 2012;100:2939-47.

12. Reakasame S, Trapani D, Detsch R, Boccaccini AR. Cell laden alginate-keratin based composite microcapsules containing bioactive glass for tissue engineering applications. J Mater SciMater M. 2018;29:185.

13. Emami Z, Ehsani M, Zandi M, Foudazi R. Controlling alginate oxidation conditions for making alginate-gelatin hydrogels. Carbohyd Polym. 2018;198:509-17.

14. Trappmann B, Gautrot JE, Connelly JT, Strange DGT, Li Y, Oyen ML. et al. Extracellular-matrix tethering regulates stem-cell fate. Nat Mater. 2012;11:642-9.

15. Duan B, Hockaday LA, Kang KH, Butcher JT. 3D bioprinting of heterogeneous aortic valve conduits with alginate/gelatin hydrogels. J Biomed Mater Res A. 2013;101:1255-64. 